\title{
Oxaliplatin long-circulating liposomes improved therapeutic index of colorectal carcinoma
}

\author{
Chuang Yang ${ }^{1,2}$, Hai Z Liư ${ }^{3}$, Zhong X Fư ${ }^{1 *}$, Wei D Lư
}

\begin{abstract}
Background: Cytotoxic drugs are non-selective between normal and pathological tissue, and this poses a challenge regarding the strategy for treatment of tumors. To achieve sufficient antitumor activity for colorectal carcinoma, optimization of the therapeutic regimen is of great importance. We investigated the ability of oxaliplatin long-circulating liposomes (PEG-liposomal L-oHP) to provide an improved therapeutic index of colorectal carcinoma.

Results: We determined that PEG- liposomes conjugated with cells at $2 \mathrm{~h}$, with a mean fluorescence intensity that was enhanced upon extended induction time. The PEG-liposomal L-OHP induced a significant apoptotic response as compared with free L-oHP, $23.21 \% \pm 3.38 \%$ vs. $16.85 \% \pm 0.98 \%$, respectively. Fluorescence imaging with In-Vivo Imaging demonstrated that PEG- liposomes specifically targeted tumour tissue. After intravenous injections of PEGliposomal L-oHP or free L-oHP, the tumour volume suppression ratio was $26.08 \% \pm 12.43 \%$ and $18.19 \% \pm 7.09 \%$, respectively, the percentage increased life span (ILS\%) was $45.36 \%$ and $76.19 \%$, respectively, and Bcl-2, Bax mRNA and protein expression in tumour tissue was 0.27 -fold vs. 0.88-fold and 1.32-fold vs. 1.61-fold compared with free $\mathrm{L}-\mathrm{OHP}$, respectively.

Conclusion: The PEG-liposomal L-oHP exhibited a tendency to target tumour tissue and demonstrated a significantly greater impact on apoptosis compared to free oxaliplatin.
\end{abstract}

\section{Background}

Colorectal carcinoma (CRC) is the third most common form of cancer in the world, and the rectum exhibits common internal malignancies [1]. Oxaliplatin (L-oHP) is a third generation platinum antitumor compound. Clinically, it is now approved as first-line chemotherapy in combination with other antitumor drugs for the treatment of advanced colorectal cancer [2,3]. It contains a bulky carrier ligand within its structure, and forms DNA adducts that more effectively inhibit DNA synthesis; however, these adducts are generally considered to be more cytotoxic than those of either cisplatin or carboplatin [4,5]. Cytotoxic drugs exhibit obvious toxicity on the human body, affecting neurotoxicity, gastrointestinal reaction, and cardiotoxicity, etc. [6]; moreover, the nonselective nature of cytotoxic drugs regarding normal and pathological tissue poses a challenge for the treatment

\footnotetext{
* Correspondence: fzx990521@sina.com

'Department of Gastrointestinal Surgery, First Affiliated Hospital, Chongqing Medical University, Chongqing 400016, Chongqing, China Full list of author information is available at the end of the article
}

of tumors. Conventional chemotherapy is not as effective in colorectal cancer as it is in other cancers since the drug does not reach the target site in an effective concentration $[7,8]$. Thus, effective treatment demands an increased dose, which may lead to negative side effects. If drugs were targeted to the tumor cells, these limitations would be overcome, and this in turn would be advantageous for the cancer treatment.

Liposomes are small, spherically shape vesicles that can be produced from cholesterols, non-toxic surfactants, sphingolipids, glycolipids, long chain fatty acids and even membrane proteins. Liposomes were among the first nanomolecular drug delivery systems to demonstrate the increased delivery of small molecular weight anticancer drugs to solid tumors by altering the biodistribution of associated drugs $[9,10]$. It has been previously reported that liposomes attach to cellular membranes and appear to fuse with them, thus releasing their contents into the cells [11]. Alternatively, liposomes are taken up by the cell, their phospholipids are incorporated into the cell membrane, and the drug
Ciomed Central

(c) 2011 Yang et al; licensee BioMed Central Ltd. This is an Open Access article distributed under the terms of the Creative Commons Attribution License (http://creativecommons.org/licenses/by/2.0), which permits unrestricted use, distribution, and reproduction in any medium, provided the original work is properly cited. 
trapped inside is then released [12]. Common liposomes, though, were in the body for only a short duration, and many were phagocytized by the reticuloendothelial system (RES). However, the 1,2-distearoyl-sn-glycero3-phosphoethanolamine-N-[maleimide(polyethylene glycol)-2000] (DSPE-PEG2000) modification to the surface of a liposome potentially prevents interactions in-vivo, thus extending the circulation lifetime of the liposome [13-15]. In tumor tissue, because tumor cells grow so quickly, newly formed tumor vessels are comprised of poorly-aligned and defective endothelial cells with wide fenestrations that lack a smooth muscle layer and innervation with the wider lumen. Furthermore, tumor tissues usually lack effective lymphatic drainage [16]. Tumor microvessel permeability is $400 \sim 600 \mathrm{~nm}$ with permeability for macromolecules having a molecular weight of $2.5 \times 10^{4} \sim 16 \times 10^{4} \mathrm{Da}$ [17]. These factors lead to abnormal molecular and fluid transport dynamics. Therefore, enhancement of the extravasation of certain sizes of molecules, such as macromolecular drugs or liposomes, leads to a much greater accumulation in tumour tissue versus normal tissue. Due to the tumor selective enhanced permeability and retention effect (EPR), this results in extensive extravasation of the liposomes $[16,18]$. In solid tumours, the EPR effect is a universal phenomenon in which liposomes are passively targeted to tumour tissue, ultimately leading to enhanced accumulation of the liposomes in the tumor interstitium [19].

Recently, FAD of USA approved a few liposomal products, such as Evacet, AM Bison, and doxorubicin in a long-circulating PEG-coated liposome. There have been initial reports indicating that the use of individual functionalities has been demonstrated to be associated with highly positive clinical outcomes [20-22]. However, there is currently no commercially available PEG-liposomal L-oHP product, and studies are still in the experimental stage. There are few reports published regarding PEGliposomal L-oHP treatment of colorectal cancer. Here, we investigated the therapeutic tumour targeting activity of PEG-liposomal L-oHP in-vitro in SW480 cells and in-vivo in a nude mice solid tumour model.

\section{Results}

Characteristics of long-circulating liposomes (PEGliposomes) and cellular uptake

We selected an increased particle size of PEG-liposomes through a series of filtration steps using a polycarbonate membrane filter at a pore size of $100 \mathrm{~nm}$. PEG-liposomes with a particle size of $151.56 \pm 15.57$ $\mathrm{nm}$ and zeta-potential of $-23.68 \pm 2.35 \mathrm{mv}$ were obtained, as determined by laser grain size analysis. The entrapment efficiency of the liposomes was $(42.96 \pm 6.45) \%$ as determined by HPLC. These values are higher than those reported recently by another group. Flow cytometry demonstrated that after incubation in medium containing Dio-labeled liposomes for $2 \mathrm{~h}$, the PEG-liposomes conjugated with cells, and exhibited an enhanced mean fluorescence intensity upon extended induction time; the mean fluorescence intensity at $24 \mathrm{~h}$ was 3.28 -fold greater than the intensity measured at $2 \mathrm{~h}$. The immunofluorescence assay revealed considerable aggregation of liposomes within cells at $24 \mathrm{~h}$ (Figure 1).

\section{In-vitro drug release and cell viability assay}

We used the dialysis method to evaluate L-oHP release from encapsulated PGE-liposomes in-vitro, and the drug concentration was then analyzed by HPLC. The cumulative percentage release demonstrated that the amount of drug released from PEG-liposomes was gradually increased over time, and after $120 \mathrm{~h}$ there was an increase of over $89 \%$. The free drug exhibited the highest level (94\%) at $2 \mathrm{~h}$, confirming the fact that PEGliposomes act as a barrier against diffusion of hydrophilic drugs.

The viability of cells was analyzed by the MTT colorimetric assay after treatment with empty PEG-liposomes $(2.6 \mu \mathrm{mol} / \mathrm{ml})$, free L-oHP $(28 \mu \mathrm{g} / \mathrm{ml})$ and PEG-liposomal L-oHP (containing L-oHP $28 \mu \mathrm{g} / \mathrm{ml}$ ), respectively. Cell viability was decreased with the length of exposure, with a maximum reduction occurring at $12 \mathrm{~h}$. The empty PEG-liposomes exhibited significantly less cytotoxicity.

\section{Analysis of apoptosis}

Upon exposure of SW480 cells to free L-oHP or PEGliposomal L-oHP, cellular apoptosis was assessed by flow cytometry, which demonstrated that PEG-liposomal L-oHP induced SW480 apoptotic incidence of (23.21 \pm 3.38 )\% (Figure 2A). The gel electrophoretic analysis of internucleosomal DNA fragmentation demonstrated the presence of primarily high molecular weight DNA as seen with the untreated control. A DNA ladder pattern, the typical feature of apoptosis, was distinctly observed (Figure 2B).

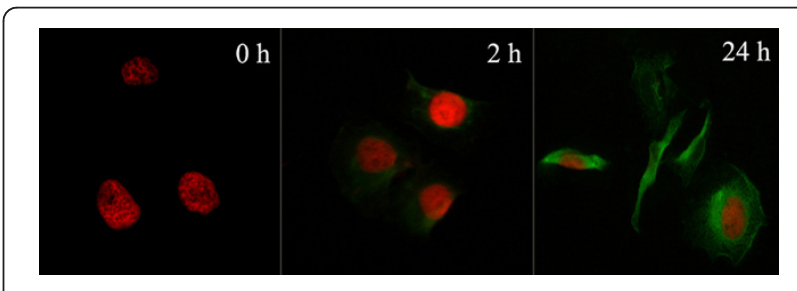

Figure 1 Cellular uptake of liposomes. The liposomes conjugated with cells after $2 \mathrm{~h}$, and cellular uptake of liposomes increased over time. Cells were incubated with Pl, which stained nuclei red, and Dio-labelled liposomes, which were green in colour. A considerable number of liposomes aggregated within cells at $24 \mathrm{~h}(\times 400)$. 


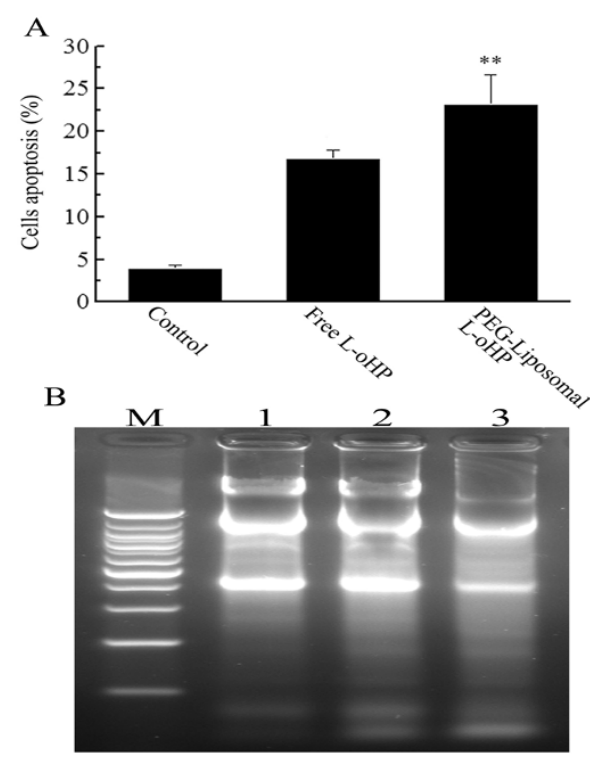

Figure 2 Apoptosis of SW480 cells. SW480 cells treated with free L-oHP $(28 \mu \mathrm{g} / \mathrm{ml})$ or PEG-Liposomal L-oHP (containing L-oHP $28 \mu \mathrm{g}$ / $\mathrm{ml}$ ), PEG-Liposomal L-oHP induced marked apoptosis compared with free L-oHP $(P<0.01)$. A, flow cytometery; B, DNA fragmentation. M: marker (4000 bp). 1: Control. 2: Free L-oHP. 3: PEG-liposomal L-oHP.

\section{Tumour tissue and Dio-labeled liposomes}

Dio-labeled liposomes were intravenously injected via the tail vein (after injection, all mice survived), and then visualized in the tumour tissue by an in-vivo imaging system. After 12 h, 24 h, 48 h, and 72 h, typical representative images were captured (Figure 3 ). The fluorescence intensity distribution of tumour tissue in the animals was indicated by green fluorescence. The fluorescence intensity was maintained at a high level for an extended period of $24 \mathrm{~h}$. However, immediately following intravenous injections, little fluorescence was observed, excluding part of the tail. The fluorescence was observed through $72 \mathrm{~h}$, indicating that PEGliposomes may continue accumulation.

\section{In-vivo antitumor effect of PEG-liposomal L-oHP}

Rapid tumour growth was observed in the mouse control group; however, significant tumor growth suppression was demonstrated in mice treated with PEG-liposomal L-oHP (Figure 4A). The tumour suppression was (26.08 \pm 12.43$) \%$, and PEG-liposomal L-oHP demonstrated the strongest effect on the survival time - all of the mice treated with PEG-liposomal L-oHP became long-term survivors (Figure $4 \mathrm{~B})(\mathrm{p}<0.01)$. Throughout the therapeutic experiment, a noticeable cachexia condition was observed in the control group, and although no bodyweight loss was observed in any of the treated groups, weight loss was significant in the control group



(data not show). These results suggest that treatment with PEG-liposomal L-oHP improves the median survival time (MST) of tumor-bearing mice without causing remarkable toxicity.

\section{Bcl-2, Bax mRNA and protein expression in tumour tissue}

To elucidate whether the growth inhibitory effect of PEG-liposomal L-oHP was attributable to the induction of apoptosis, Bcl-2 and Bax were analyzed by RT-PCR or Western blot in tumour tissue. On day 15 after treatment, tumours were resected and total RNA and protein were extracted from the tumour tissue. Our experiments demonstrated that mRNA expression levels of Bcl-2 were remarkably decreased in the PEG-liposomal L-oHP group; 0.27-fold compared with free L-oHP, whereas, Bax mRNA increased 1.32-fold compared with free L-oHP (Figure 5A). Protein expression tendency of Bcl-2 and Bax were 0.88-fold and 1.61-fold in comparison, respectively (Figure $5 \mathrm{~B}$ ). These results indicated that apoptosis was strongly induced by PEG-liopsomal L-oHP.

\section{Discussion}

The non-selectivity of cytotoxic drugs between normal tissue and the pathological site poses a tumor treatment strategy challenge. To obtain increased therapeutic efficacy, a drug carrier must achieve increased delivery of 

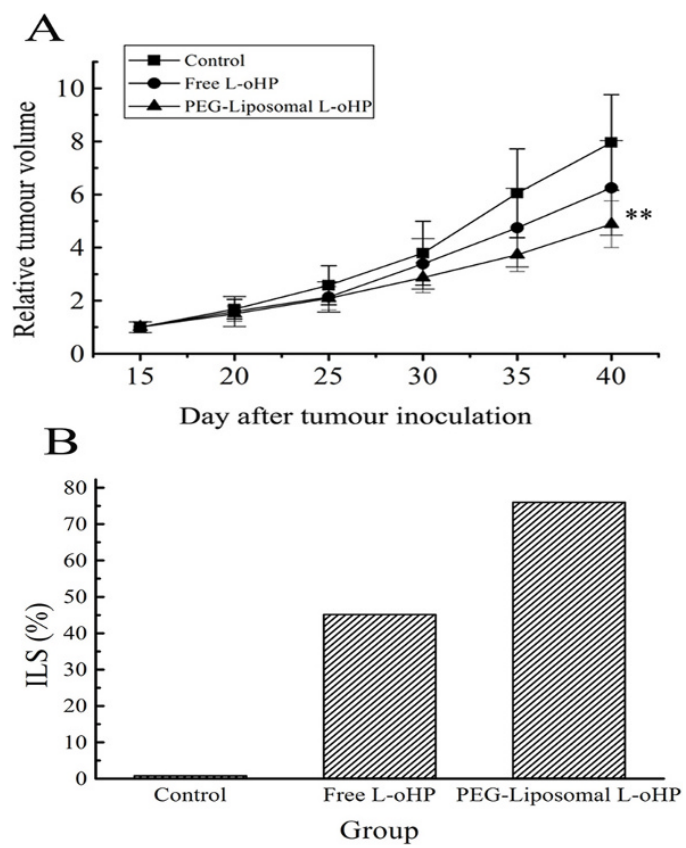

Figure 4 Tumor growth suppression and survival time. On day 12 after tumour inoculation, mice were treated ith free L-oHP (5 $\mu \mathrm{g} / \mathrm{g}$ ), PEG-liposomal L-oHP (containing L-oHP $5 \mu \mathrm{g} / \mathrm{g}$ ), or $5 \%$ dextrose solution. Antitumor activity as assessed by tumour size and survival of tumour-bearing mice. A, Relative tumor volume (RTV), data represent mean $\pm S D(n=6) .{ }^{*} P<0.01$ compared with the other group. B, The percentage increase in life span (ILS\%).

the drug to the tumor tissue, while also allowing for enhanced interaction of the drug with, and subsequent internalization by, tumor cells. Liposomes, as carriers of chemotherapeutic agents, are able to change the distribution of these agents within the body and decrease their toxicity $[23,24]$. Therefore, drug-loaded liposomes offer a new approach for the treatment of colorectal cancer.

Polyethylene glycol (PEG)-coated liposomes (PEGliposomes), are stable and not easy to be taken up by cells of the reticuloendothelial system (RES), and exhibit reduced drug leakage compared with conventional liposomes [25]. It has been previously reported that PEG modification of liposomes increases their affinity to cancer cells and increases the cellular uptake of drugs [26-28]. The toxicity of PEG-liposomes for cells should be taken into consideration, and some previous reports have indicated that the toxicity is indeed lower $[29,30]$. In our experiment, the empty PEG-liposomes in-vitro exhibited significantly less cytotoxicity for SW480 cells. The tumour cells took up large numbers of PEG- liposomes, which is in concordance with reports by other groups [31]. However, PEG-liposomes containing a drug increase toxicity. Our MTT assays showed that PEGliposomal L-oHP (containing L-oHP $28 \mu \mathrm{g} / \mathrm{ml}$ ) had significantly greater cytotoxic effects than free oxaliplatin $(28 \mu \mathrm{g} / \mathrm{ml})$. When we assessed their effects on apoptosis, as determined by flow cytometry and the DNA Ladder method, we observed that, at an identical dose, PEGliposomal L-oHP demonstrated a significantly greater effect on apoptosis than did free L-oHP. PEG-liposomes exhibited tumour-targeted delivery in these cells.

Previous studies have demonstrated that PEGmodified liposomes act primarily through vesicular organelles, and are preferentially taken up by angiogenic tumour endothelium [32]. To obtain sufficient antitumor activity with liposomal anticancer drugs, optimization of the therapeutic regimen is of great importance.
A
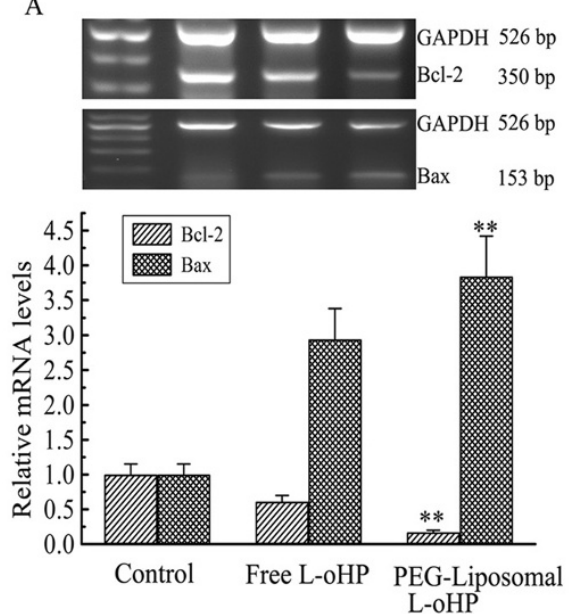

B
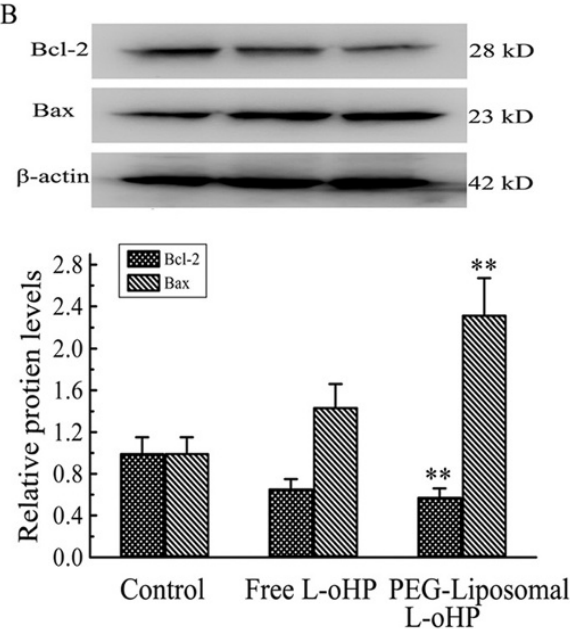

Figure 5 The mRNA and protein expression of Bcl-2 and Bax in tumour tissue. On day 15 after treatment, the total mRNA and protein was extracted from tumour tissue. A, The mRNA expression. Agarose gel electrophoresis result shown in which expression of Bcl-2 is down-regulated and expression of Bax is up-regulated; B, The protein expression. Cell lysates were separated on 12\% SDS-PAGE gels, BCl-2 was down-regulated, whereas Bax was up-regulated. Data are expressed as mean $\pm S D(n=3)$. ${ }^{*} P<0.01$ compared with the other group. 
In solid tumours (during the rapid growth of the tumour in particular), the permeability of the vasculature is generally increased compared to normal tissues $[32,33]$. Therefore, these may provide a channel allowing liposomes to more easily target tumour tissue. After receiving intravenous injections of Dio-labeled PEGliposomes, mice were able to survive. Experiments presented in this study indicate that PEG-liposomes efficiently accumulate in tumor tissue (Figure 3 ), and maintain a high level over $24 \mathrm{~h}$, which is in concordance with previous reports from other groups [31,34]. Furthermore, the fluorescence remained detectable even after $72 \mathrm{~h}$. The plasma clearance of anionic molecules occurred more slowly than for cationic molecules [35]. Based upon evidence from the in-vitro cell experiments and the mouse tumour model, a higher concentration and longer blood residence time of liposomes would result in greater efficiency of extravasation per unit volume of convective transport [36,37], and this would explain the fact that liposomes remain in the tumor tissue.

Additionally, to investigate the treatment availability of PEG-liposomal L-oHP, Bcl-2 and Bax were evaluated. Bcl-2 and Bax are members of the Bcl-2 family, Bax is a proapoptotic protein that induces mitochondrial outer membrane permeabilization (MOMP), causing the release of caspase activating proteins. In contrast, $\mathrm{Bcl}-2$ is an anti-apoptotic protein and guardian of the outer membrane and it preserves its integrity by opposing Bax; they are associated with apoptosis necrosis, and autophagy, and regulate all major types of cell death $[38,39]$. We used the level of genes and protein to indicate treatment results. After treatment with PEG-liposomal L-oHP, tumour cell predominance of apoptosis in tumorbearing nude mice was induced, and Bcl-2 mRNA and protein expression were down-regulated, whereas Bax was up-regulated (Figure 5). This demonstrated that such liposomal L-oHP formulation exhibits potent in-vivo antitumor activity, presumably via a dual targeting approach against both tumour endothelial cells and tumour cells $[40,41]$.

The PEG-liposomal L-oHP accumulated in the tumour tissue, following uptake by endothelial cells as well as tumor cells, and liposomes were then degraded, while intracellular drug delivery increased the concentration of drug within cells and slowed drug efflux [42-44]. These findings indicate that liposome encapsulation of chemotherapeutic drugs enhances their damaging effects on tumour cells. At present, FDA approved liposomal products (Evacet, doxorubicin liposomes, etc.) have the advantage of high encapsulation efficiency, rapid release rate, and so forth. As to our study, further research is needed in order to improve drug encapsulation efficiency and stability, as well as further studies involving dynamic research in a clinical setting.

\section{Conclusion}

The experiments presented in this report indicate that PEG-liposomal L-oHP achieves a better therapeutic response than the equivalent dose of free L-oHP, and it indicates the potentially wide application for this type of drug target for tumors and other tissues, with the advantage of the ability to overcome some major limitations in conventional anticancer chemotherapy. This study may provide the rationale for the clinical application of CRC. Nevertheless, further studies are warranted to elucidate the underlying molecular mechanism.

\section{Methods}

\section{Animals and tumor cell line}

Female BALB/c nude mice, 3 weeks old, were obtained from Center of Laboratory Animals, Chongqing Medical University (Permit Number: SCXK(jing) 2009-0004). All animal experiments were evaluated and approved by the Animal and Ethics Review Committee. The human colorectal carcinoma cell line (SW480) was obtained from the Institute of Life Science of Chongqing Medical University, and it was maintained in RPMI 1640 (Sigma, St. Louis, MO) supplemented with $10 \%$ fetal bovine serum (FBS) (HyClone, Logan, UT) in a $5 \% \mathrm{CO}_{2}$ incubator at $37^{\circ} \mathrm{C}$.

\section{Preparation of liposomes}

PEG-liposomes were prepared using lecithin (Sigama Co., US), cholesterol (Sigama Co., US), and DSPEPEG2000 (Avanti Polar Lipids Inc. US) as previously described [31]. The molar ratio was 2.0:1.0:0.2. In the targeting experiments, $2 \mathrm{nmol} / \mathrm{ml}$ of the fluorescent lipid membrane marker, Dio (Vigorous Biotech Co. Ltd. China), was added to the lipid mixture. The liposomes were prepared using the reverse-phase evaporation method. Briefly, lipids (50 mmol) were dissolved in $15 \mathrm{ml}$ of chloroform and then $5 \mathrm{ml}$ of L-oHP solution $(1 \mathrm{mg} / \mathrm{ml})$ in $5 \%(\mathrm{w} / \mathrm{v})$ dextrose was dropped into the lipid mixture to form W/O emulsion. For preparation of no drug-containing liposomes, $5 \%$ dextrose solution was added instead of L-oHP solution. The volume ratio of the aqueous to the organic phase was maintained at 1:3. The emulsion was sonicated for $10 \mathrm{~min}(40 \mathrm{~W})$ and then the organic phase was removed to form the liposomes by evaporation in a rotary evaporator at $40^{\circ} \mathrm{C}$ under vacuum at $0.045 \mathrm{mPa}$ for $2 \mathrm{~h}$. The resulting liposomes were extruded through a polycarbonate membrane (Millipore, US. $100 \mathrm{~nm}$ pore size).

The grade size and zeta-potential were detected by Laser Particle Size Analyzer (Zetasizer, Malvern). Using a transmission electron microscope (Hitachi S-3000N, 
japan), the form feature of PEG-liposomes was determined. The free L-oHP was removed by ultrafiltration (MW $100 \mathrm{kDa}, 12,000 \mathrm{r} / \mathrm{min} 20 \mathrm{~min}$ ). The entrapment efficiency of the liposomes was determined by highperformance liquid chromatography (HPLC, SY-8100, Beijin, China). In-vitro drug release from PEG-liposomes was studied using a dialysis method as described by Zhang et al. [45].

\section{Cellular uptake of Dio-labeled PEG-liposomes}

SW480 cells were seeded onto 6-well plates in $1 \mathrm{ml}$ of RPMI 1640 medium containing 10\% FBS and preincubated for $24 \mathrm{~h}$. After removal of culture medium, $1 \mathrm{ml}$ of fresh medium containing the Dio-labeled PEGliposomes $(2 \mu \mathrm{mol} / \mathrm{ml})$ was added, followed by incubation at $37^{\circ} \mathrm{C}$. At $0,2,4,8,12$ and $24 \mathrm{~h}$ post-incubation, the cells were trypsinized, followed by two washes with cold phosphate buffered saline (PBS). The cells were resuspended in $400 \mu \mathrm{l}$ of PBS $\left(1 \times 10^{6} / \mathrm{ml}\right)$. The cellular uptake of Dio-labeled liposomes was quantified using a flow cytometer (FACS Aria, Becton, Dickinson and Company), equipped with an argon-ion laser and $488 \mathrm{~nm}$ band pass filters for emission measurements. Approximately 10,000 events were acquired per sample. Cells were also plated onto glass slides and incubated with Dio-labeled liposomes, and the cellular uptake of liposomes was determined by measuring fluorescence.

\section{Cytotoxicity assay}

Cytotoxicity of L-oHP formulations was determined by the 3-(4,5-dimethylthiazol-2-yl)-2,5 diphenyl tetrazolium bromide (MTT) assay, as described previously [33]. Briefly, cells in the logarithmic growth phase $\left(5 \times 10^{3}\right.$ per well) were placed in wells of a 96-well plate and incubated for $24 \mathrm{~h}$. The culture medium was replaced with fresh medium containing various concentrations of blank liposomes, free oxaliplatin, or PEG-liposomal L-oHP. After treatment, the culture medium was removed and the cells were incubated with MTT (final concentration $10 \%$ ) for $4 \mathrm{~h}$ at $37^{\circ} \mathrm{C}$. Then $150 \mu \mathrm{l}$ DMSO was added to each well to dissolve formazan crystals. The absorbance of each well was read at $570 \mathrm{~nm}$ on a microplate reader, and used to determine IC50 values (IC50 values represent L-oHP concentrations that cause $50 \%$ cell death). The concentration of oxalipatin liposomes was expressed as $1 / 2$ the IC50 of the working concentration of oxaliplatin.

\section{Detection of apoptosis by flow cytometry}

SW480 cells cultured in 6-well plates were treated with free oxaliplatin $(28 \mu \mathrm{g} / \mathrm{ml})$ or PEG-liposomal L-oHP (containing L-oHP $28 \mu \mathrm{g} / \mathrm{ml}$ ) for $12 \mathrm{~h}$, along with a blank control with no drug treatment. The cells were trypsinized, followed by two washes with cold PBS, re-suspended in $400 \mu \mathrm{l}$ of PBS $\left(1 \times 10^{6} / \mathrm{ml}\right)$, and incubated in the dark for $15 \mathrm{~min}$ following addition of Annexin V-FITC $(5 \mu \mathrm{l})$. Cells were subsequently treated with PI $(10 \mu \mathrm{l})$ and incubated in the dark for $5 \mathrm{~min}$ prior to detection by flow cytometry. Approximately 10,000 events were acquired per sample.

\section{DNA fragmentation analysis for detecting apoptosis}

For DNA fragmentation assay, cells were treated as described above. Adherent and floating cells were recovered and DNA was isolated and evaluated for fragmentation as described previously [46]. DNA samples were applied on $1.5 \%$ agarose gel containing $1 \%$ GoldView $^{\mathrm{TM}}$. The gel was examined and photographed using an ultraviolet gel documentation system (Bio-Rad, Hercules, CA, USA).

\section{Targeting of Dio-labeled liposomes in tumor-bearing nude mice}

Female BALB/c nude mice were inoculated subcutaneously at the inguen region with SW480 Cells $\left(2 \times 10^{7} /\right.$ mouse $)$ in a volume of $200 \mu \mathrm{l}$ (PBS). On day 15 after tumor inoculation, the tumor volume reached approximately $100 \mathrm{~mm}^{3}$. Next, intravenous injections of Dio-labeled PEG-liposomes $(0.5 \mu \mathrm{mol} / \mathrm{g})$ were performed via the tail vein. At $12 \mathrm{~h}, 24 \mathrm{~h}, 48 \mathrm{~h}$, and $72 \mathrm{~h}$ post-injection, nude mice were anesthetized with isoflurane, and fluorescence imaging was performed using the In-Vivo Imaging System (Mastro Ex, USA) which has an affiliated anesthesia device.

\section{Therapeutic efficacy of PEG-liposomal L-oHP in tumor-bearing nude mice}

After successful subcutaneously inoculated tumor transplantation, the nude mice were randomly divided into three groups. Control $(n=6)$ : Received intravenous injections of $5 \%$ dextrose solution; Free L-oHP $(n=6)$ : Received intravenous injections of $5 \mu \mathrm{g} \mathrm{L}-\mathrm{oHP} / \mathrm{g}$; PEG-liposomal L-oHP $(\mathrm{n}=6)$ : Received intravenous injections of PEG-liposomal L-oHP (containing L-oHP $5 \mu \mathrm{g} / \mathrm{g}$ ). Treatments occurred once every four days, and the antitumor activity was evaluated in terms of both relative tumor volume (RTV) and the percentage of increased life span (ILS\%). Tumor volume was calculated using the method described by Kim [47] and the ILS was calculated using the method described by Kviecinski [48]. The median survival time (MST) of each group was recorded.

\section{Reverse transcription-polymerase chain reaction (RT-PCR)} On day 15 after treatment, the nude mice were sacrificed by deep anesthesia, and the tumours were immediately placed in liquid nitrogen for further experiments. Total RNA was extracted using TRIZOL (Takara, 
Dalian, China). Reverse transcription was carried out in $10 \mu \mathrm{l}$ of reaction mixture containing $1 \mu \mathrm{g}$ of total RNA, 25 pmol of oligo-dT primer, $10 \mathrm{nmol}$ of dNTP mixture, 20 units of RNase inhibitor, and 2.5 units of AMV reverse transcriptase (Takara, Dalian, China) at $37^{\circ} \mathrm{C}$ for $15 \mathrm{~min}, 85^{\circ} \mathrm{C}$ for $5 \mathrm{~s}$. PCR amplification was performed in $25 \mu \mathrm{l} \mathrm{PCR}$ reaction mixture. PCR amplification was conducted to detect differences among the samples as follows: $4 \mathrm{~min}$ at $94^{\circ} \mathrm{C}$ for initial denaturation; 30 cycles $\times$ $30 \mathrm{~s}$ at $94^{\circ} \mathrm{C}, 30 \mathrm{~s}$ at $59^{\circ} \mathrm{C}$, and $30 \mathrm{~s}$ at $72^{\circ} \mathrm{C}$ for Bcl-2, Bax; 30 cycles $\times 30 \mathrm{~s}$ at $94^{\circ} \mathrm{C}, 30 \mathrm{~s}$ at $60^{\circ} \mathrm{C}$, and $30 \mathrm{~s}$ at $72^{\circ} \mathrm{C}$ for GAPDH. The following primer pairs were used: Bax (153 bp): 5'-GAT CGA GCA GGG CGA ATG GG-3' (ForwardPrimer); 5'-CAC GGC GGC AAT CAT CCT CT-3' (ReversePrimer); Bcl-2 (350 bp): 5'-CAG ATG GCA AAT GAC CAG CAGA-3' (ForwardPrimer), 5'-TGG CAG GAT AGC AGC ACA GGAT-3' (ReversePrimer); GAPDH (526 bp): 5'-AGG TCG GAG TCA ACG GAT TTG-3' (ForwardPrimer), 5'-GTG ATG GCA TGG ACT GTG GT-3' (ReversePrimer). For the analysis of PCR products, $6 \mu \mathrm{l}$ of each PCR reaction was electrophoresed on $1.5 \%$ agarose gel containing $1 \%$ GoldView $^{\mathrm{TM}}$. Band intensity was analyzed with Image system (NIH, USA) and GAPDH was used as an internal control to evaluate the relative expression of $\mathrm{Bcl}-2$ and $\mathrm{Bax}$.

\section{Western blot analysis}

For isolation of total protein extract, tumour tissues were washed with ice-cold PBS and lysed in RIPA lysis buffer $(50 \mathrm{mM}$ Tris with $\mathrm{pH} 7.4,150 \mathrm{mM} \mathrm{NaCl}, 1 \%$ Triton X-100, $1 \%$ sodium deoxycholate, $0.1 \%$ sodium dodecyl sulphate, and $0.05 \mathrm{mM}$ EDTA) for $30 \mathrm{~min}$ on ice, and then the cell lysate was centrifuged $(12,000$ $\mathrm{revs} / \mathrm{min}$, at $4^{\circ} \mathrm{C}$ ) for $10 \mathrm{~min}$. The supernatant was collected and protein content of the extracted samples was measured using the Bradford protein assay kit (BestBoBeiBo, Beijing, China). All samples were kept at $-80^{\circ} \mathrm{C}$ for further experiments.

Levels of target proteins including Bcl-2, Bax (Santa Cruz Biotechnology, Inc. 1:200), and $\beta$-actin (Bioscience Company of America, 1:500) were determined by Western blot analysis using their respective antibodies. Briefly, total cell lysate was boiled in $5 \times$ loading buffer (125 mM Tris-HCl, pH 6.8, 10\% SDS, 8\% dithiothreitol, $50 \%$ glycerol, and $0.5 \%$ bromchlorphenol blue) for $10 \mathrm{~min}$. Equal amounts of proteins $(50 \mu \mathrm{g})$ were subjected to $12 \%$ SDS-polyacrylamide gel electrophoresis and transferred to polyvinylidene fluoride membranes (PVDF). The membranes were blocked with $5 \%$ skim milk in PBS with $0.1 \%$ Tween 20 (PBST) for $1 \mathrm{~h}$, and incubated with primary antibodies overnight at $4{ }^{\circ} \mathrm{C}$. Antibodies were detected by means of HRP-conjugated secondary antibody (Bioscience Company of America, 1:2000) for $1 \mathrm{~h}$ at room temperature. Immunoreactive bands were visualized using Immobilon ${ }^{\mathrm{TM}}$ Western Chemiluminescent HRP Substrate (Millipore, USA), and densitometric analysis was performed using the PDI Imageware System (Bio-Rad, Hercules, CA, USA).

\section{Abbreviations}

CRC: Colorectal carcinoma; SDS-PAGE: Sodium Dodecyl SulfatePolyacrylamide Gel Electrophoresis; L-oHP: Oxaliplatin; DSPE-PEG2000: 1,2distearoyl-sn-glycero-3-phosphoethanolamine- N-[maleimide(polyethylene glycol)-2000]; MTT: 3-(4,5)-dimethylthiahiazo (-z-y1)-3,5-di-

Phenytetrazoliumromide; HPLC: High-performance liqued chromatography; DAB: 3,3'-diaminobenzidine; Dio: $\operatorname{DIOC}_{18}(3), 3,3$ ' dioctadecyloxacarbocyanine perchlorate; RES: Reticuloendothelial system EPR: Enhanced permeability and retention; MOMP: Mitochondrial outer membrane permeabilization; FBS: Fetal bovine serum; RTV: Relative tumor volume; ILS: Increased life span; MST: Median survival time; PVDF: Polyvinylidene fluoride membranes.

\section{Acknowledgements}

This work was supported by a grant (No. 09-2-12) from the Health Administration of Chongqing. We thank Xin $\mathrm{H}$ Jiang for the expert technical assistance with HLPC, and we are grateful to the Central Lab, the Ophthalmological Lab of Chongqing Medical University First Affiliated Hospital, and the College of Life Science of Chongqing Medical University for the technical support.

\section{Author details}

${ }^{1}$ Department of Gastrointestinal Surgery, First Affiliated Hospital, Chongqing Medical University, Chongqing 400016, Chongqing, China. ${ }^{2}$ Department of Hepatobiliary Surgery, Mianyang Third People's Hospital, Mianyang 621000, Sichuan Province, China. ${ }^{3}$ Departments of Gynecology and Obstetrics, Second Affiliated Hospital, Chongqing Medical University, Chongqing 400016, Chongqing, China.

\section{Authors' contributions}

CY was responsible for most of the experimental work and drafted the manuscript. ZF participated in the design, supervised this study, and was involved in revising the manuscript. HL participated in culturing cells, performing Western blot detection, and assisting in the statistical analysis. WL was involved with the animal model experiment. All authors read and approved the final manuscript.

Received: 28 September 2010 Accepted: 15 March 2011 Published: 15 March 2011

\section{References}

1. Nobili S, Checcacci D, Filippelli F, Del Buono S, Mazzocchi V, Mazzei T, Mini E: Bimonthly chemotherapy with oxaliplatin, irinotecan, infusional 5-fluorouracil/folinic acid in patients with metastatic colorectal cancer pretreated with irinotecan-or oxaliplatin-based chemotherapy. J Chemother 2008, 20:622-631.

2. Ibrahim A, Hirschfeld S, Cohen MH, Griebel DJ, Williams GA, Pazdur R: FDA drug approval summaries: oxaliplatin. Oncologist 2004, 9:8-12

3. Pessino A, Sobrero A: Optimal treatment of metastatic colorectal cancer, Expert Rev. Anticancer Ther 2006, 6:801-812.

4. Basaki Y, Chikahisa L, Aoyagi K, Miyadera K, Yonekura K, Hashimoto A, Okabe S, Wierzba K, Yamada Y: Gamma-hydroxybutyric acid and 5fluorouracil, metabolites of UFT, inhibit the angiogenesis induced by vascular endothelial growth factor. Angiogenesis 2001, 4:163-173.

5. Tashiro T, Kawada Y, Sakurai Y, Kidani Y: Antitumor activity of a new platinum complex, oxalato (trans-I-1,2-diaminocyclohexane)platinum (II): new experimental data. Biomed Pharmacother 1989, 43:251-260.

6. Pasetto LM, D'Andrea MR, Rossi E, Monfardini S: Oxaliplatin-related neurotoxicity: how and why? Crit Rev Oncol Hematol 2006, 59:159-168.

7. Michor F, Iwasa Y, Lengauer C, Nowak NA: Dynamics of colorectal cancer. Semin Cancer Biol 2005, 15:484-493.

8. Pietrangeli A, Leandri M, Terzoli E, Jandolo B, Garufi C: Persistence of highdose oxaliplatin-induced neuropathy at long-term follow-up. Eur Neurol 2006, 56:13-16. 
9. Hussain S, Pluckthun A, Allen TM, Zangemeister-Wittke U: Antitumor activity of an epithelial cell adhesion molecule targeted nanovesicular drug delivery system. Mol Cancer Ther 2007, 6:3019-3027.

10. Sun W, Zou W, Huang G, Li A, Zhang N: Pharmacokinetics and targeting property of TFu-loaded liposomes with different sizes after intravenous and oral administration. J Drug Target 2008, 16:357-365.

11. Dunnick JK, Rooke JD, Aragon S, Kriss JP: Alteration of mammalian cells by interaction with artificial lipid vesicles. Cancer Res 1976, 36:2385-2389.

12. Poste G, Papahadjopoulos D: Lipid vesicles as carriers for introducing materials into cultured cells: influence of vesicle lipid composition on mechanism(s) of vesicle incorporation into cells. Proc Natl Acad Sci USA 1976, 73:1603-1607.

13. Allen TM, Hansen C, Martin F, Redemann C, Yau-Young A: Liposomes containing synthetic lipid derivatives of poly(ethylene glycol) show prolonged circulation half-lives in vivo. Biochim Biophys Acta 1991, 1066:29-36.

14. Klibanov AL, Maruyama K, Beckerleg AM, Torchilin VP, Huang L: Activity of amphipathic poly(ethylene glycol) 5000 to prolong the circulation time of liposomes depends on the liposome size and is unfavorable for immunoliposome binding to target. Biochim Biophys Acta 1991, 1062:142-148.

15. Allen C, Dos Santos N, Gallagher R, Chiu GN, Shu Y, Li WM, Johnstone SA, Janoff AS, Mayer LD, Webb MS, Bally MB: Controlling the physical behavior and biological performance of liposome formulations through use of surface grafted poly(ethylene glycol). Biosci Rep 2002, 22:225-250.

16. Greish K: Enhanced permeability and retention (EPR) effect for anticancer nanomedicine drug targeting. Methods Mol Biol 2010, 624:25-37.

17. Yuan F, Dellian M, Fukumura D: Vascular perme-ability in a human tumor xenograft: molecular size dependence and cutoff size. Cancer Res 1995, 55:3752-3756.

18. Maeda H, Bharate GY, Daruwalla J: Polymeric drugs for efficient tumortargeted drug delivery based on EPR-effect. Eur J Pharm Biopharm 2009, 71:409-419.

19. Fang J, Sawa T, Maeda H: Factors and mechanism of "EPR" effect and the enhanced antitumor effects of macromolecular drugs including SMANCS. Adv Exp Med Biol 2003, 519:29-49.

20. HHarrington KJ, Lewanski C, Northcote AD, Whittaker J, Peters AM, Vile RG, Stewart JS: Phase II study of pegylated liposomal doxorubicin (Caelyx) as induction chemotherapy for patients with squamous cell cancer of the head and neck. Eur J Cance 2001, 37:2015-2022.

21. Seiden MV, Muggia F, Astrow A, Matulonis U, Campos S, Roche M, Sivret J, Rusk J, Barrett E: A phase II study of liposomal lurtotecan (OSI-211) in patients with topotecan resistant ovarian cancer. Gynecol Oncol 2004, 93:229-232.

22. Torchilin VP: Recent advances with liposomes as pharmaceutical. carriers. Nat Rev Drug Discov 2005, 4:145-160.

23. Desai SK, Naik SR: Preparation, relative toxicity, chemotherapeutic activity, and pharmacokinetics of liposomal SJA-95: a new polyene macrolide antibiotic. J Liposome Res 2008, 18:279-92.

24. Rouf MA, Vural I, Renoir JM, Hincal AA: Development and characterization of liposomal formulations for rapamycin delivery and investigation of their antiproliferative effect on MCF7 cells. J Liposome Res 2009, 19:322-31.

25. Gabizon A, Papahadjopoulos D: Liposome formulations with prolonged circulation time in blood and enhanced uptake by tumors. Proc Natl Acad Sci USA 1988, 85:6949-6953.

26. Gabizon AA: Stealth liposomes and tumor targeting: a step further in the quest for the magic bullet. Clin Cancer Res 2001, 7:223-225.

27. Zalipsky S, Brandeis E, Newman MS, Woodle MC: Long circulating, cationic liposomes containing amino-PEG-phosphatidylethanolamine. FEBS Lett 53:71-74, 994.

28. Cheong I, Zhou S: Tumor-specific liposomal drug release mediated by liposomase. Methods Enzymol 2009, 465:251-265.

29. Singh S: Nanomedicine-nanoscale drugs and delivery systems. J Nanosci Nanotechnol 2010, 10:7906-1918.

30. Abu Lila AS, Kizuki S, Doi Y, Suzuki T, Ishida T, Kiwada H: Oxaliplatin encapsulated in PEG-coated cationic liposomes induces significant tumor growth suppression via a dual-targeting approach in a murine solid tumor model. J Control Release 2009, 137:8-14.

31. Zhang G, Yang Z, Lu W, Zhang R, Huang Q, Tian M, Li L, Liang D, Li C: Influence of anchoring ligands and particle size on the colloidal stability and in vivo biodistribution of polyethylene glycol-coated gold nanoparticles in tumor-xenografted mice. Biomaterials 2009, 30:1928-1936.

32. Thurston G, Mclean JW, Rizen M, Baluk P, Haskell A, Murphy TJ, Hanahan D, Mcdonald DM: Cationic liposomes target angiogenic endothelial cells in tumours and chronic inflammation in mice. J Clin Invest 1998, 101:1401-1413.

33. Yuan F, Dellian M, Fukumura D: Vascular perme-ability in a human tumor xenograft: molecular size dependence and cutoff size. Cancer Res 1995, 55:3752-3756.

34. Doi $Y$, Okada T, Matsumoto H, Ichihara M, Ishida T, Kiwada H: Combination therapy of metronomic S-1 dosing with oxaliplatin-containing polyethylene glycol-coated liposome improves antitumor activity in a murine colorectal tumor model. Cancer Sci 2010, 101:2470-2475.

35. Dellian M, Yuan F, Trubetskoy VS, Torchilin VP, Jain RK: Vascular permeability in a human tumour xenograft: molecular charge dependence. British Journal of Cancer 2000, 82:1513-1518.

36. Alexis F, Pridgen E, Molnar LK, Farokhzad OC: Factors affecting the clearance and biodistribution of polymeric nanoparticles. Mol Pharm 2008, 5:505-515.

37. Grant DS, Williams TL, Zahaczewsky M, Dicker AP: Comparison of antiangiogenic activities using paclitaxel (taxol) and docetaxel (taxotere). Int J Cancer 2003, 104:121-129.

38. John C, Reed: Bcl-2-family proteins and hematologic malignancies: history and future prospects. Blood 2008, 111:3322-3330.

39. Chipuk JE, Fisher JC, Dillon CP, Kriwacki RW, Kuwana T, Green DR: Mechanism of apoptosis induction by inhibition of the anti-apoptotic BCL-2 proteins. PNAS 2008, 105:20327-20332.

40. Lee CM, Tanaka T, Murai T, Kondo M, Kimura J, Su W, Kitagawa T, Ito T, Matsuda H, Miyasaka M: Novel chondroitin sulfate-binding cationic liposomes loaded with cisplatin efficiently suppress the local growth and liver metastasis of tumor cells in vivo. Cancer Res 2002, 62:4282-4288.

41. Jain A, Jain SK, Ganesh N, Barve J, Beg AM: Design and development of ligand-appended polysaccharidic nanoparticles for the delivery of oxaliplatin in colorectal cancer. Nanomedicine: NBM 2010, 6:179-190.

42. Abu-Lila A, Suzuki T, Doi Y, Ishida T, Kiwada H: Oxaliplatin targeting to angiogenic vessels by PEGylated cationic liposomes suppresses the angiogenesis in a dorsal air sac mouse model. J Control Release 2009, 134:18-25.

43. Saito R, Bringas JR, MCKnight TR, Wendland MF, Mamot C, Drummond DC, Kirpotin DB, Park JW, Berger MS, Bankiewicz KS: Distribution of Liposomes into Brain and Rat Brain Tumor Models by Convection-Enhanced Delivery Monitored with Magnetic Resonance Imaging. Cancer research 2004, 64:2572-2579.

44. Katriina L, Riitta M, Jari K, Ilpo J, Stina S: Intracellular Distribution of Oligonucleotides Delivered by Cationic Liposomes: Light and Electron Microscopic Study. The Journal of Histochemistry \& Cytochemistry 1997, 45:265-274.

45. Zhang JA, Anyarambhatla G, Ma L, Ugwu S, Xuan T, Sardone T, Ahmad I: Development and characterization of a novel Cremophor EL free liposome-based paclitaxel (LEPETU) formulation. Eur J Pharm Biopharm 2005, 59:177-187.

46. El-Mahdy MA, Zhu Q, Wang QE, Wani G, Wani AA: Thymoquinone induces apoptosis through activation of caspase- 8 and mitochondrial events in p53-null myeloblastic leukemia HL-60 cells. Int J Cancer 2005, 117:409-417

47. Kim JH, Kim YS, Park K, Lee S, Nam HY, Min KH, Jo HG, Park JH, Choi K, Jeong SY, Park RW, Kim IS, Kim K, Kwon IC: Antitumor efficacy of cisplatinloadedglycol chitosan nanoparticles in tumor-bearing mice. J Control Release 2008, 127:41-49.

48. Kviecinski MR, Felipe KB, Schoenfelder T, de Lemos Wiese LP, Rossi MH, Goncalez E, Felicio JD, Filho DW, Pedrosa RC: Study of the antitumor potential of Bidens pilosa (Asteraceae) used in Brazilian folk medicine. J Ethnopharmacol 2008, 117:69-75.

doi:10.1186/1472-6750-11-21

Cite this article as: Yang et al:: Oxaliplatin long-circulating liposomes improved therapeutic index of colorectal carcinoma. BMC Biotechnology 2011 11:21. 